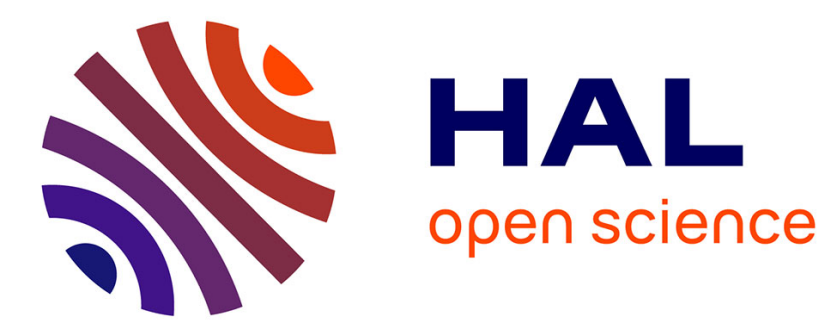

\title{
La conférence expérimentale sommeil et travail à horaires atypiques : une mise en situation inédite de $5 \mathrm{~h}$ à $13 \mathrm{~h}$
}

Eric Mullens, Marc Delanoe, Didier Gourc, Ludivine Leseux

\section{- To cite this version:}

Eric Mullens, Marc Delanoe, Didier Gourc, Ludivine Leseux. La conférence expérimentale sommeil et travail à horaires atypiques : une mise en situation inédite de $5 \mathrm{~h}$ à $13 \mathrm{~h}$. Médecine du sommeil, 2015, 12 (1), pp.56 - 57. 10.1016/j.msom.2015.01.102 . hal-01773901

\section{HAL Id: hal-01773901 \\ https://hal.science/hal-01773901}

Submitted on 19 Nov 2018

HAL is a multi-disciplinary open access archive for the deposit and dissemination of scientific research documents, whether they are published or not. The documents may come from teaching and research institutions in France or abroad, or from public or private research centers.
L'archive ouverte pluridisciplinaire HAL, est destinée au dépôt et à la diffusion de documents scientifiques de niveau recherche, publiés ou non, émanant des établissements d'enseignement et de recherche français ou étrangers, des laboratoires publics ou privés. 


\title{
La conférence expérimentale sommeil et travail à horaires atypiques : une mise en situation inédite de $5 \mathrm{~h}$ à $13 \mathrm{~h}$
}

\author{
Eric Mullens ${ }^{1}$, Marc Delanoe ${ }^{2}$, Didier Gourc ${ }^{3}$, Ludivine Leseux ${ }^{4}$
}

(1) Laboratoire du Sommeil, Fondation Bon Sauveur, Albi, France

(2) Santé Sécurité au Travail, MSA Midi Pyrénées Nord, Albi, France

(3) École des Mines d'Albi-Carmaux, Albi, France

(4) SADIR association, Toulouse, France

\section{Objectif}

Les médecins du sommeil connaissent depuis longtemps les effets délétères du manque de sommeil en relation notamment avec le travail à horaires atypiques. En mai 2012 la Haute Autorité de santé a recommandé d'informer les travailleurs et le CHSCT sur l'ensemble des risques identifiés. Cela a permis au Laboratoire du Sommeil en collaboration avec l'École des Mines d'Albi et la Société de médecine du travail Midi-Pyrénées d'initier une expérience innovante. Le but étant de placer l'assistance dans la situation de privation de sommeil d'un poste du matin pour sensibiliser les managers et les acteurs de prévention en entreprises (APE) aux conséquences du manque de sommeil sur la santé physique, mentale et sur la pénibilité. Nous avons élaboré des questionnaires d'évaluation soumis aux participants pendant les conférences et les siestes.

\section{Méthodes}

Treize conférences de spécialistes du sommeil, médecins du travail, psychologue, chef d'entreprise, sportif de haut niveau, enseignant-chercheur. Tout au long de la conférence, les participants répondent, par boîtiers électroniques interactifs, à 30 questions et tests de vigilance. Six ateliers sieste d'1 h sont organisés à partir de $6 \mathrm{~h} 30$. Une pause repas à $9 \mathrm{~h}$ avec présentation de matériels de traitement des apnées du sommeil. Nous proposons dans cet article une analyse des réponses entre siesteurs/non-siesteurs (S/NS).

\section{Résultats}

Cent soixante-douze participants (70\% de femmes) : managers $15 \%$, APE $67 \%$. Vingt-deux pour cent se sont levés avant 3 h, $89 \%$ ont dormi moins de 6 h, $28 \%$ ont un score d'Epworth $>10$. Près de $38 \%$ font des journées de plus de $17 \mathrm{~h}, 23 \%$ somnolent au volant, $34 \%$ ronflent, $39 \%$ ne font jamais la sieste, par manque de temps pour $49 \%$. Enfin, $42 \%$ des participants ont ressenti une baisse de leur vigilance entre 7 et $9 \mathrm{~h}$. Parmi les 49 candidats S, $37 \%$ ont eu l'impression d'avoir dormi et $70 \%$ d'avoir fait le vide. Après la pause, seulement $10 \%$ des S ont ressenti une baisse de vigilance contre $30 \%$ des NS $\left(\mathrm{Chi}^{2}=13,52, p=0,035\right)$.

\section{Conclusion}

Neuf participants sur 10 pensent que cette conférence contribuera à modifier leur pratique professionnelle. L'atelier sieste a eu un effet positif sur la vigilance. Dossier complet et vidéo sur http://eric.mullens.free.fr. 